\title{
Comparison of cholesterol and $\beta$-sitosterol: effects on jejunal fluid secretion induced by oleate, and absorption from mixed micellar solutions
}

\author{
T SLOTA, N A KOZLOV, AND H V AMMON \\ From the Department of Medicine, Veterans Administration Center, Wood (Milwaukee), Wisconsin, and the \\ Medical College of Wisconsin, Milwaukee, Wisconsin, USA
}

SUMMARY Jejunal fluid secretion induced by perfusion with oleic acid can be reduced by the addition of cholesterol. The present study was performed to test the specificity of this effect by comparing the effects of cholesterol with that of a plant sterol, $\beta$-sitosterol during perfusion of the jejunum in healthy volunteers. In addition, we compared the solubilities of cholesterol and $\beta$-sitosterol in micellar solutions and their jejunal absorption rates. One millimolar $\beta$-sitosterol was as effective as $1 \mathrm{mM}$ cholesterol in reducing jejunal fluid secretion induced by $6 \mathrm{mM}$ oleate $(\mathrm{n}=7)$. In mixed micellar solutions consisting of $10 \mathrm{mM}$ taurocholate and $6 \mathrm{mM}$ oleate, solubility of $\beta$-sitosterol is about one third of cholesterol solubility. When cholesterol was gradually replaced by $\beta$-sitosterol in the incubation mixture, $\beta$-sitosterol reduced cholesterol solubility to a greater extent than would be expected from an equimolar replacement of cholesterol by $\beta$-sitosterol. Absorption of $\beta$-sitosterol was limited by its solubility in mixed micellar solutions and both sterols were absorbed at equal rates as long as their solubility limits were not exceeded $(n=5)$.

Long chain fatty acids induce intestinal fluid and electrolyte secretion in man and experimental animals. ${ }^{1-4}$ In addition, they reduce absorption of organic solutes in the jejunum and ileum..$^{34}$ These effects are thought to be responsible for the diarrhoea in certain malabsorption states. ${ }^{5}$ We reported recently that cholesterol reduces the effects of oleic acid and taurodeoxycholate on jejunal water and solute transport. ${ }^{6}$ To test whether this observation is specific for cholesterol, the present study compares the effects of cholesterol on fluid secretion induced by oleate with those of $\beta$-sitosterol, a plant sterol. The experiments provided in addition the opportunity to compare the absorption of cholesterol and $\beta$-sitosterol during in vivo perfusion. Sitosterol absorption has not been studied in perfusion studies before. In feeding experiments it is poorly absorbed. ${ }^{7}$ Because it has been used therapeutically to reduce cholesterol absorption ${ }^{8}$ we also studied the effects of $\beta$-sitosterol on the solubility of cholesterol in mixed micelluar solutions.

Address correspondence and requests for reprints to: Helmut V Ammon. MD. Gastroenterology Section/111C. Veterans Administration Medical Center Wood (Milwaukee). Wisconsin, 53193, USA.

Received for publication 11 October 1982

\section{Methods}

MATERIALS

Taurocholate was synthesised as described previously..$^{9}$ The purity of the final product was greater than $98 \%$ by thin layer chromatography. Cholic acid was purchased from Sigma Chemical Company (St. Louis, MO). Oleic acid (cis-9octadecenoic acid) and cholesterol (both with a purity of greater than $99 \%$ ) were obtained from $\mathrm{Nu}$ Check Prep (Elysian, MN). $\beta$-sitosterol (5cholesten-24 $\beta$-ethyl-3 $\beta$-ol) (purity greater than 98\%) was obtained from Applied Science Laboratories (State College, PA), $\left[1,2-{ }^{14} \mathrm{C}\right]$-polyethylene glycol, $\left[4-{ }^{14} \mathrm{C}\right]$-cholesterol and $\left[22,23-{ }^{3} \mathrm{H}(\mathrm{N})\right] \quad \beta$ sitosterol from New England Nuclear (Boston, MA).

\section{SOLUBILITY STUDIES}

The solubilities of cholesterol and $\beta$-sitosterol were determined in a solution containing $10 \mathrm{mM}$ taurocholate and $6 \mathrm{mM}$ oleate in $20 \mathrm{mM}$ sodium phosphate buffer, $\mathrm{pH} 7.4$, and $120 \mathrm{mM}$ sodium chloride. One hundred micromoles taurocholate, 6 $\mu \mathrm{mol}$ oleic acid, and $4 \mu \mathrm{mol}$ sterols were dissolved 
in chloroform: methanol, (v/v $2: 1)$ in $20 \mathrm{ml}$ screw cap vials. The molar ratios of ${ }^{14} \mathrm{C}$-cholesterol (specific activity $18 \mu \mathrm{Ci} / \mathrm{mmol}$ ) to ${ }^{3} \mathrm{H} \beta$-sitosterol (specific activity $90 \mu \mathrm{Ci} / \mathrm{mmol}$ ) in the mixtures were $4: 0,3: 1,2: 2,1: 3$ or $0: 4$. The solvent was evaporated under nitrogen. The dry precipitates were resuspended in $10 \mathrm{ml}$ of $20 \mathrm{mM}$ sodium phosphate buffer with $120 \mathrm{mM} \mathrm{NaCl}$ (pH 7.4). The incubation flasks were shaken for four days under argon atmosphere at $37^{\circ} \mathrm{C}$. Sterol solubility was determined by filtration through a $220 \mathrm{~m} \mu$ Millipore filter. ${ }^{10}$ The final concentrations of cholesterol and $\beta$-sitosterol were calculated from the isotope ratios in the filtrates. All incubations were performed in triplicate, all isotope determinations in duplicate.

\section{PERFUSION TECHNIQUE}

Jejunal perfusion studies were performed in healthy male volunteers who gave informed written consent. The protocol was approved on 28 September 1977 by the Human Studies Committees of the Veterans Administration Center, Wood, Wisconsin and the Medical College of Wisconsin, Milwaukee, Wisconsin. The perfusion technique, previously described, ${ }^{1}{ }^{6}$ uses a 4-lumen tube with an occluding balloon at the ligament of Treitz. Perfusion solutions were delivered at $37^{\circ} \mathrm{C}$ at a constant rate of $10 \mathrm{ml}$ per minute just distal to the balloon and sampled $25 \mathrm{~cm}$ distally by siphonage. Duodenal contents proximal to the balloon were removed by intermittent suction. An additional gastric tube was inserted for aspiration of gastric secretions. Control and test solutions were perfused for 60 minutes. The first 30 minutes were used for equilibration. Samples were collected for six consecutive five-minute intervals. Steady-state conditions were confirmed by stable concentrations of polyethyleneglycol (PEG) during these sequential sampling periods and all results refer to observations during the steady state. ${ }^{136}$ The means of the six sampling periods constitute one data point.

\section{COMPOSITION OF PERFUSION SOLUTIONS}

Perfused were isotonic electrolyte solutions which contained (in mmol/l): $\mathrm{Na} 130, \mathrm{~K} 5, \mathrm{Cl} 119$, glucose $11 \cdot 2$, taurocholate 10 (for micellar solubilisation), PEG-4000 $5 \mathrm{gm} / 1$ with $\left[1,2-{ }^{14} \mathrm{C}\right] \mathrm{PEG} 4 \mu \mathrm{Ci} / 1$ as non-absorbable marker. In addition the solutions contained varying concentrations of oleate, cholesterol, or $\beta$-sitosterol (see below).

\section{ANALYTICAL METHODS}

PEG was determined as ${ }^{14} \mathrm{C}$-PEG. ${ }^{11}$ One millilitre of the perfusate was mixed with $10 \mathrm{ml}$ of a scintillation cocktail (Ready Solv-HP, Beckman Instruments Inc., Fullerton, CA) and counted in a liquid scintillation counter (Beckman Model LS255). Quench correction was made by external standardisation. Counts per minute were converted into disintegrations per minute with a computer program which corrected for quenching and spillover of ${ }^{14} \mathrm{C}$ into the tritium channel. ${ }^{12}$ Spillover of tritium into the ${ }^{14} \mathrm{C}$ channel was less than $1 \%$. Oleic acid was measured by gas liquid chromatography of its methyl ester after acid extraction into a toluene ethanol mixture $(2: 1)$ containing heptadecanoic acid as internal standard. ${ }^{16}$ Sterols in the perfusion solutions were measured by gas liquid chromatography after alkaline extraction into a toluene ethanol mixture $(2: 1)$ containing cholestane as an internal standard. ${ }^{13}$ Glucose was measured by the glucose-oxidase method (Boehringer-Mannheim Corp, New York, NY).

\section{CALCULATIONS AND STATISTICAL ANALYSIS}

Net water and solute movements were calculated using standard formulas from the changes in PEG and solute concentrations. Results are expressed as mean ( \pm standard error). Net water movement is expressed as $\mathrm{ml} / \mathrm{min}$ per $25 \mathrm{~cm}$ and solute absorption as $\mu \mathrm{mol} / \mathrm{min}$ per $25 \mathrm{~cm}$. Differences in net movement of water and solutes were evaluated statistically by paired $t$ test.

\section{Results}

SOLUBILITY OF CHOLESTEROL AND $\beta$-SITOSTEROL Figure 1 describes the solubility of cholesterol and $\beta$-sitosterol in mixed micellar solutions. Under the experimental conditions, maximum solubility of cholesterol alone was almost three times as great as that of $\beta$-sitosterol. The addition of sitosterol to the incubation mixture reduced cholesterol solubility below that predicted by an equimolar replacement of cholesterol by sitosterol, that is, the total amount of sterols solubilised in the presence of $\beta$-sitosterol was less than the amount of cholesterol that could have been solubilised in the absence of $\beta$-sitosterol.

EFFECT OF CHOLESTEROL AND $\beta$-SITOSTEROL ON FLUID SECRETION IN THE PRESENCE OF OLEATE (Experiment 1) (Table 1)

Three solutions were perfused in random sequence in seven volunteers. Solution (1) contained $6 \mathrm{mM}$ oleate; solution (2) contained in addition $1 \mathrm{mM}$ cholesterol, and solution (3) $1 \mathrm{mM} \beta$-sitosterol. Net fluid secretion occurred in the presence of $6 \mathrm{mM}$ oleate. The addition of either sterol to the perfusion solution reduced fluid secretion significantly $(p<0.005)$. There was no difference between the effects of cholesterol and $\beta$-sitosterol. Glucose absorption was enhanced with reduced fluid secre- 


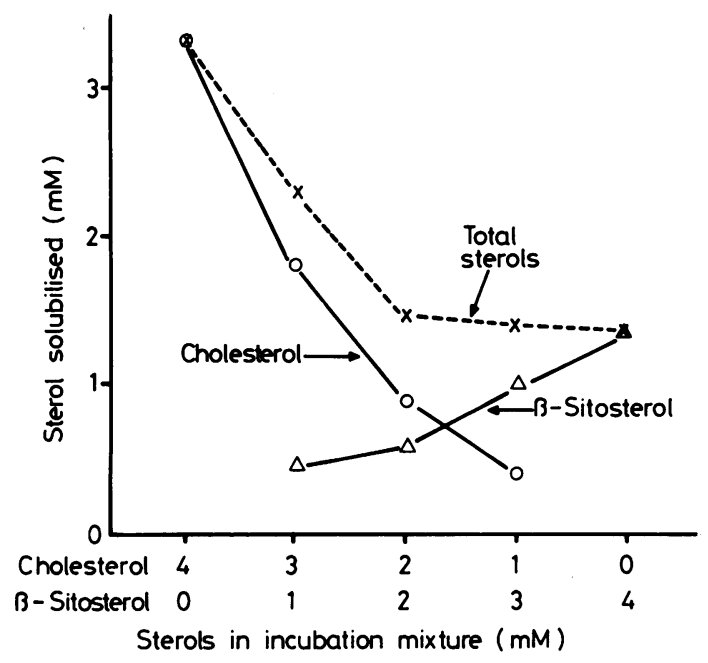

Fig. 1 Solubility of cholesterol and $\beta$-sitosterol in mixed micellar solutions containing $10 \mathrm{mmol}$ taurocholate and 6 mmol oleate. $\beta$-sitosterol reduced the solubility of cholesterol below concentration predicted by an equimolar replacement of cholesterol by $\beta$-sitosterol.

tion; this enhancement was statistically significant during perfusion with $\beta$-sitosterol $(\mathrm{p}<0 \cdot 01)$. Fatty acid absorption did not change significantly. Cholesterol was absorbed at almost twice the rate of $\beta$-sitosterol $(\mathrm{p}<0.005)$.

ABSORPTION OF CHOLESTEROL AND $\beta$-SITOSTEROL FROM MIXED MICELLAR SOLUTIONS (Experiment 2) (Table 2)

To define, whether the absorption rates for $\beta$ sitosterol and cholesterol were owing to the different solubility limits of the two sterols, we studied in five volunteers the absorption of (1) 0.25 $\mathrm{mM}$ cholesterol, (2) $0.25 \mathrm{mM} \beta$-sitosterol and (3) a combination of $0.125 \mathrm{mM}$ cholesterol and $\beta$ - sitosterol from solutions containing $4 \mathrm{mM}$ of oleate. Four millimolar oleate was chosen because previous studies had shown that no significant fluid secretion is induced by that fatty acid concentration. ${ }^{1}$ The sterol concentration in this experiment was well below the solubility limits for either sterol. Water and fatty acid absorption during all three experimental situations were about equal. There was no difference between the absorption rates of cholesterol and $\beta$-sitosterol when either sterol was perfused alone or during the perfusion of both sterols simultaneously.

To test whether the solubility limits for the two sterols explained the lower absorption rates of $\beta$-sitosterol in experiment 1 , we plotted the concentrations of oleate $v s$ cholesterol and $\beta$-sitosterol at the sampling site in experiment 1 and experiment 2 (Fig. 2). The figure also shows the solubility limits for each sterol in relation to fatty acid concentration. These lines are extrapolations from the solubility limits in $6 \mathrm{mM}$ oleate and $10 \mathrm{mM}$ taurocholate (Fig. 1). For the purposes of this graph the low solubility of cholesterol ${ }^{14}$ and sitosterol in taurocholate alone is set equal to zero and it is assumed that sterol solubility increases linearly with the fatty acid concentration in the solution. As taurocholate absorption in the jejunum is negligible,$^{15}$ taurocholate concentration is considered unchanged for purposes of this analysis. During experiment $1 \beta$-sitosterol concentrations at the distal end of the test segment were at or above its solubility limits in five out of seven studies in contrast with only one out of five studies in experiment 2. Cholesterol concentrations remained well below its solubility limits under all experimental conditions.

\section{Discussion}

We have shown that $\beta$-sitosterol is as effective as

Table 1 Effect of $\beta$-sitosterol on fluid secretion in the presence of oleate in the human jejunum

\begin{tabular}{|c|c|c|c|}
\hline \multirow[b]{2}{*}{ Net transport per $25 \mathrm{~cm}$} & \multicolumn{3}{|c|}{ Test conditions ( $m M)$} \\
\hline & $\begin{array}{l}\text { I } \\
\text { Oleate (6) }\end{array}$ & $\begin{array}{l}\text { II } \\
\text { Oleate (6) + } \\
\text { Cholesterol (1) }\end{array}$ & $\begin{array}{l}\text { III } \\
\text { Oleate (6) }+ \\
\beta \text {-sitosterol (1) }\end{array}$ \\
\hline $\begin{array}{l}\mathrm{H}_{2} \mathrm{O}(\mathrm{ml} / \mathrm{min})^{*} \\
\text { Glucose }(\mu \mathrm{mol} / \mathrm{min}) \\
\text { Oleic acid }(\mu \mathrm{mol} / \mathrm{min}) \\
\text { Cholesterol }(\mu \mathrm{mol} / \mathrm{min}) \\
\beta \text {-sitosterol }(\mu \mathrm{mol} / \mathrm{min})\end{array}$ & $\begin{array}{l}-1 \cdot 6 \pm 0 \cdot 4 \\
64 \cdot 2 \pm 5 \cdot 7 \\
31 \cdot 8 \pm 3 \cdot 5 \\
-\end{array}$ & $\begin{array}{l}-0 \cdot 2 \pm 0 \cdot 3 \dagger \\
70 \cdot 7 \pm 5 \cdot 0 \\
30 \cdot 1 \pm 3 \cdot 3 \\
2 \cdot 0 \pm 0 \cdot 2 \\
-\end{array}$ & $\begin{array}{c}-0 \cdot 1 \pm 0 \cdot 3 \dagger \\
76 \cdot 9 \pm 7 \cdot 4 \ddagger \\
33 \cdot 2 \pm 3 \cdot 4 \\
- \\
1 \cdot 1 \pm 0 \cdot 2 \S\end{array}$ \\
\hline
\end{tabular}

* - = net secretion. $\nmid \mathrm{p}<0.005$ vs I. $\ddagger \mathrm{p}<0.01$ vs $\mathrm{I}$. $\$ \mathrm{p}<0.005$ vs cholesterol.

Data are mean $\pm S E$ from studies in seven healthy volunteers. Each solution was perfused for one hour at $10 \mathrm{ml} / \mathrm{min}$. The perfusion sequence was randomised. 
Table 2 Absorption of cholesterol and $\beta$-sitosterol from micellar solutions in the human jejunum

\begin{tabular}{|c|c|c|c|c|c|}
\hline \multirow[b]{2}{*}{ Test conditions $(m M)^{*}$} & \multicolumn{5}{|c|}{ Net transport $/ 25 \mathrm{~cm}$} \\
\hline & $\begin{array}{l}\mathrm{H}_{2} \mathrm{O} \\
\mu \mathrm{mol} / \mathrm{min}\end{array}$ & $\begin{array}{l}\text { Glucose } \\
\text { umol/min }\end{array}$ & 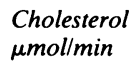 & $\begin{array}{l}\beta \text {-sitosterol } \\
\mu \mathrm{mol} / \mathrm{min}\end{array}$ & Oleate \\
\hline \multirow{3}{*}{$\begin{array}{l}\text { Cholesterol } 0.25 \\
\beta \text {-sitosterol } 0.25 \\
\text { Cholesterol } 0.125+ \\
\beta \text {-sitosterol } 0.125\end{array}$} & $0.5 \pm 0.4$ & $67 \cdot 4 \pm 7 \cdot 7$ & $0 \cdot 6 \pm 0 \cdot 1$ & - & $28 \cdot 1 \pm 2 \cdot 1$ \\
\hline & $0 \cdot 6 \pm 0 \cdot 5$ & $73 \cdot 8 \pm 12 \cdot 9$ & - & $0 \cdot 4 \pm 0 \cdot 1$ & $23 \cdot 8 \pm 3 \cdot 9$ \\
\hline & $0 \cdot 8 \pm 0 \cdot 4$ & $73 \cdot 5 \pm 8 \cdot 5$ & $0 \cdot 2 \pm 0 \cdot 1$ & $0 \cdot 2 \pm 0 \cdot 0$ & $25 \cdot 6 \pm 3 \cdot 7$ \\
\hline
\end{tabular}

Data are mean $\pm S E$ from studies in five voluntecrs.

${ }^{*}$ All solutions contained $10 \mathrm{mM}$ taurocholate and $4 \mathrm{mM}$ olcatc for micellar solubilisation of sterols

cholesterol in reducing jejunal fluid secretion induced by oleate. In addition these studies show that $\beta$-sitosterol is less soluble than cholesterol in mixed micellar solutions and that it reduces the solubility of cholesterol. $\beta$-sitosterol is absorbed as fast as cholesterol, provided that its solubility limits are not exceeded.

Although the current experiments do not provide a fatty acid free control period, the fluid secretion in the presence of $6 \mathrm{mM}$ oleate can be attributed to the fatty acid in view of our earlier studies ${ }^{36}$ and in view of the fact that water absorption was observed in the presence of $4 \mathrm{mM}$ oleate (Table 2). The data indicate that the ability of cholesterol to reduce fatty acid-induced fluid secretion ${ }^{6}$ is not limited to this sterol. In other model systems $\beta$-sitosterol can also substitute for cholesterol. For instance, $\beta$-sitosterol

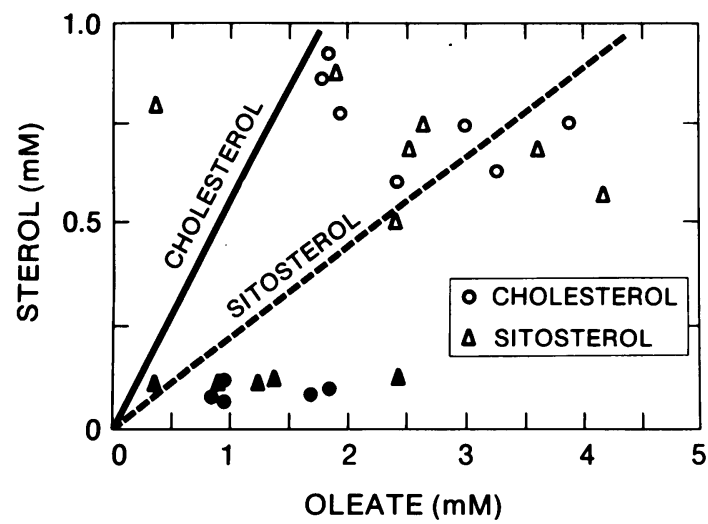

Fig. 2 Concentrations of cholesterol and $\beta$-sitosterol in relation to that of oleate at the distal end of the test segment during perfusion of the human jejunum. All solutions contained $10 \mathrm{mM}$ taurocholate. In experiment 1 (open symbols) the perfusion solutions contained $6 \mathrm{mM}$ oleate and $1 \mathrm{mM}$ sterol, in experiment 2 (closed symbols) $4 \mathrm{mM}$ oleate and $0.25 \mathrm{mM}$ sterol. The dotted and solid lines indicate the solubility limits for cholesterol and $\beta$-sitosterol under these conditions. supports the growth of sterol-dependent mycoplasmas. ${ }^{16}$ The present observation, therefore, is consistent with our hypothesis that cholesterol in the intestinal lumen exerts its protective effect by stabilisation of the lipid bilayer membrane of the enterocytes. ${ }^{6}$ This hypothesis is based on the fact that fatty acids have detergent properties ${ }^{17}$ and that cholesterol reduces detergent effects on red blood cells $^{18}$ and stabilises phospholipid bilayer membranes in liposomes exposed to membraneperturbing agents. ${ }^{19}$ The fact that sitosterol was less rapidly absorbed than cholesterol does not argue against the proposed mechanism by which sterols reduce fluid secretion induced by fatty acids, because the absorption rate of sterols does not necessarily reflect their concentration in the cell membrane of the enterocyte.

The structural requirements for sterols as membrane stabilising agents are a planar sterol nucleus, a 3- $\beta$ hydroxyl group and a side chain $;^{20}$ these are all met by $\beta$-sitosterol. In previous studies we had shown that reduction of monomer activities of fatty acids by cholesterol cannot explain our in vivo observations. ${ }^{6}$ Intracellular effects are also unlikely, although not completely excluded, in view of the observation that $\beta$-sitosterol is as effective as cholesterol in spite of a significantly lower absorption rate (Table 1$)$.

The enhancement of glucose absorption in the presence of cholesterol or $\beta$-sitosterol is consistent with our previous observations, that fatty acids reduce absorption of glucose in addition to their effects on water and electrolyte movement. ${ }^{3}$ A reduction of the effects on glucose absorption is therefore to be expected when fluid secretion is reduced.

The present studies suggest that significant amounts of $\beta$-sitosterol can be absorbed from micellar solutions and that a major cause for the poor absorption of $\beta$-sitosterol in comparison with cholesterol is its limited solubility in micellar solutions. Under the special conditions where 
solubility in micellar solution was maintained, the rate of absorption of $\beta$-sitosterol was equal to that of cholesterol (Table 2). This is consistent with the concept that micellar solubilisation facilitates lipid absorption. ${ }^{21}$ The data can be reconciled with results from feeding experiments, where sitosterol absorption has been consistently lower than cholesterol absorption ${ }^{722}$ because, according to our solubility studies, the sitosterol administered in triglyceride oil would have been much less soluble in micellar solution than cholesterol. Moreover, in the experiments by Sylven and Borgström ${ }^{22}$ the oil phase was markedly expanded and only $75 \%$ of the triglyceride administered was absorbed. ${ }^{2.3}$ Therefore, the greater lipid solubility of sitosterol may have favoured its presence in the oil phase in comparison with cholesterol. The data are somewhat more difficult to reconcile with the uptake studies by Sylven ${ }^{24}$ in which sitosterol uptake from micellar solutions was significantly less than that of cholesterol. The micellar solutions, however, in these experiments were made up of $10 \mathrm{mM}$ taurodeoxycholate and 10 $\mathrm{mM}$ monoolein, as micellar expander. Taurodeoxycholate in contrast to taurocholate has significant effects on the intestinal mucosa ${ }^{56}$ and sterol uptake and absorption is significantly influenced by the polar lipid used as micellar expander. ${ }^{25} 26$ Thus, the experimental conditions may not be comparable.

Our observations, of course, have the limitation that absorption was only assessed by the recovery of the perfused lipid at the sampling site. The observations will, therefore, have to be confirmed in an animal model where recovery of the absorbed sterols in the thoracic duct lymph and their absorption in the perfused test segment can be measured simultaneously.

In feeding experiments $\beta$-sitosterol significantly reduces the absorption of cholesterol ${ }^{827} 28$ and this observation has been used therapeutically. ${ }^{8}$ The mechanism by which $\beta$-sitosterol reduces the absorption of cholesterol has not been studied in detail. The solubility experiments show that the less soluble $\beta$-sitosterol reduces the solubility of cholesterol in mixed micellar solutions to a greater extent than would be expected from a mole for mole replacement of cholesterol. $\beta$-sitosterol is less soluble, probably because its more bulky tail requires more space in the hydrophobic core of the mixed micelles. This would also explain why cholesterol solubility is reduced to such a degree in the presence of $\beta$-sitosterol. As micellar solubilisation becomes rate limiting for lipid absorption, ${ }^{21}$ reduction of cholesterol solubility by the addition of sitosterol to the diet will reduce its absorption in feeding experiments or balance studies. ${ }^{27} 28$
The current observations could find some therapeutic application in attempts to control the diarrhoea of patients with steatorrhea.

This study was supported by Grant AM 17941 from the National Institutes of Health and by the Research Service of the Veterans Administration. The authors wish to thank Ms Michelle Andrade for excellent technical help.

\section{References}

1 Ammon HV, Thomas PJ, Phillips SF. Effects of oleic and ricinoleic acids on net jejunal water and electrolyte movement: perfusion studies in man. J Clin Invest 1974; 53: 374-9.

2 Bright-Asare P, Binder HJ. Stimulation of colonic secretion of water and electrolytes by hydroxy fatty acids. Gastroenterology 1973; 64: 81-8.

3 Ammon HV, Thomas PJ, Phillips SF. Effects of long chain fatty acids on solute absorption: perfusion studies in the human jejunum. Gut 1977; 18: 805-13.

4 Ammon HV, Phillips SF. Inhibition of ileal water absorption by intraluminal fatty acids. J Clin Invest 1974; 53: 205-10.

5 Binder HJ. Pathophysiology of bile acid- and fatty acid-induced diarrhea. In: Field M, Fordtran JS, Schultz SG, eds. Secretory diarrhea. Bethesda, Md: American Physiological Society 1980: 159-78.

6 Broor SL, Slota T, Ammon HV. Cholesterol reduces the effects of dihydroxy bile salts and fatty acids on water and solute transport in the human jejunum. $J$ Clin Invest 1980; 65: 920-5.

7 Salen G, Ahrens EH Jr, Grundy SM. Metabolism of $\beta$-sitosterol in man. J Clin Invest 1970; 49: 952-67.

8 Subbiah RMT. Significance of dietary plant sterols in man and experimental animals. Mayo Clin Proc 1971; 46: 549-59.

9 Hofmann AF. The function of bile salts in fat absorption. The solvent properties of dilute micellar solutions in conjugated bile salts. Biochem $J$ 1963; 89: 57-68.

10 Simmonds WJ, Hofmann AF, Theodore E. Absorption of cholesterol from a micellar solution: intestinal perfusion studies in man. J Clin Invest 1967; 46: 874-90.

11 Wingate DL, Sandberg RJ, Phillips SF. A comparison of stable and ${ }^{14} \mathrm{C}$-labelled polyethylene glycol as volume indicators in the human jejunum. Gut 1972; 13: 812-5.

12 Okita GT, Kabara JJ, Richardson F, LeRoy GR. Assaying compounds containing ${ }^{3} \mathrm{H}$ and ${ }^{14} \mathrm{C}$. Nucleonics 1957; 15: 111-4.

13 Grunwald C. Quantitative analysis of free phytosterols by gas chromatography using stationary phase OV-101. Anal Biochem 1970; 34: 16-23.

14 Tamesue N, Inoue T, Juniper K Jr. Solubility of cholesterol in bile salt-lecithin model systems. Am J Dig Dis 1973; 18: 670-8. 
15 Hislop IG, Hofmann AF, Schoenfield LJ. Determinants of the rate and site of bile acid absorption in man. J Clin Invest 1967; 46: 1070-1.

16 Nes WR. Role of sterols in membranes. Lipids 1973; 9: 596-612.

17 Shah DO. Surface chemistry of lipids. Adv Lipid Res 1970; 8: 347-429.

18 Shinozawa S, Araki Y, Utsumi D, Oda T. Stabilizing effects of cholesterol on changes in membrane permeability and potential induced in red blood cells by lysolecithin. Physiol Chem Physics 1979; 11: 161-7.

19 Pang KY, Miller KW. Cholesterol modulates the effects of membrane perturbance in phospholipid vesicles and biomembranes. Biochim Biophys Acta 1976; 457: 109-32.

20 Demel RA, DeKruyff B. The function of sterols in membranes. Biochim Biophys Acta 1978; 511: 1-9.

21 Dietschy JM, Wilson JD. Regulation of cholesterol metabolism. N Engl J Med 1970; 282: 1179-83.

22 Sylven C, Borgström B. Absorption and lymphatic transport of cholesterol and sitosterol in the rat. J Lipid Res 1969; 10: 179-82.
23 Sylven C, Borgström B. Absorption and lymphatic transport of cholesterol in the rat. J Lipid Res 1968; 9: $596-601$.

24 Sylven C. Influence of blood supply on lipid uptake from micellar solutions by the rat small intestine. Biochim Biophys Acta 1970; 203: 365-75.

25 Sylven C, Borgström B. Intestinal absorption and lymphatic transport of cholesterol in the rat: influence of the fatty acid chain length of the carrier triglyceride. J Lipid Res 1969; 10: 351-5.

26 Rampone AJ, Machida CM. Mode of action of lecithin in suppressing cholesterol absorption. J Lipid Res 1981; 22: 744-52.

27 Tangedahl TN, Thistle JL, Hofmann AF, Matseshe JW. Effect of $\beta$-sitosterol alone or in combination with chenic acid on cholesterol saturation of bile and cholesterol absorption in gallstone patients. Gastroenterology 1979; 76: 1341-46.

28 Grundy SM, Mok HYI. Effects of low dose phytosterols on cholesterol absorption in man. In: Greten H, ed. Lipoprotein metabolism. New York: Springer, 1976: $112-8$. 